\title{
Wes' Brot ich ess, des' Lied ich sing?
}

Im Mittelalter - so wird berichtet - gab es an jedem Königshof einen Hofnarren. Dieser durfte nicht nur Spässe treiben mit den Ministern und Kurtisanen, sondern als einzigem war ihm auch erlaubt, sich über den König lustig zu machen, ja ihm sogar ab und zu einen Spiegel vorzuhalten und seine Schwächen blosszustellen. Die Kunst des Hofnarren lag darin, sich bis zu jener unausgesprochenen Grenze vorzutasten (und davor Halt zu machen), an der das kritische Auf-dieSchippe-Nehmen des Königs in Majestätsbeleidigung umschlug und ihn den Kopf kosten konnte.

Die Rolle desjenigen, der dem König (bzw. der Gesellschaft) einen Spiegel vorhält, wird heute unter anderem von den Ethikern wahrgenommen. Ihre wichtige Aufgabe besteht darin, bei ethisch heiklen oder umstrittenen Bereichen kritische Fragen $\mathrm{zu}$ formulieren, verschiedene inhaltliche Positionen vergleichend nebeneinanderzustellen und auf Schwachstellen oder Lücken hinzuweisen. Die Ethiker verstehen sich selbstverständlich nicht mehr als Hofnarren, sondern als Fachleute, die mit wissenschaftlichen Methoden komplexe Fragestellungen bearbeiten.

Was aber, wenn sie, wie es häufig vorkommt, im Solde eines Königs (bzw. einer Firma oder einer Behörde) stehen - wie gehen sie mit dem Risiko um, sich um Kopf und Kragen (bzw. ein gesichertes Einkommen) zu reden? Denn auch die Könige von heute können durchaus jähzornig reagieren. Stellvertretend dafür steht eine
Geschichte aus dem Hastings Center, einem bekannten Bioethikinstitut in den Vereinigten Staaten. Der «Hastings Center Report» veröffentlichte im Jahr 2000 einen kritischen Artikel über den undifferenzierten Einsatz eines bekannten Antidepressivums. Als Konsequenz davon entzog die Firma, welche dieses Medikament herstellt, dem Hastings Center per sofort und mit Verweis auf den Artikel die bisher gewährte jährliche Unterstützung in der Höhe von 25000 Dollar.

Wie soll die Arbeit von Ethikern und Ethikerinnen bezahlt werden, ohne dass diese in Interessenskonflikte geraten oder sich in Abhängigkeiten begeben? Wie können Ethiker ihre Aufgabe als «unabhängiges Gewissen» einer Gesellschaft wahrnehmen? Diesem Thema ist eine Tagung gewidmet, welche die Schweizerische Gesellschaft für Biomedizinische Ethik am 3. Mai 2003 in Basel durchführt (weitere Informationen unter www.bioethics.ch). Unter dem Titel «Gekauftes Gewissen? Die Rolle der Bioethik in Institutionen und Unternehmen» referieren und diskutieren namhafte Fachleute aus dem In- und Ausland. Die Tagung ist selbstverständlich auch für die Ärzteschaft von Bedeutung; Interessenskonflikte und der Umgang damit sind ja nicht zuletzt auch in der Medizin zu einem lebhaft diskutierten Thema geworden.

Dr. med. Hermann Amstad stv. Generalsekretär SAMW 